\title{
Bounds on Biomass Estimates and Energetic Consequences of Ctenophora in the Northeast U.S. Shelf Ecosystem
}

\author{
Michael D. Ford ${ }^{1}$ and Jason S. Link ${ }^{2}$ \\ ${ }^{1}$ National Marine Fisheries Service, 1315 East-West Highway, Silver Spring, MD 20910, USA \\ ${ }^{2}$ National Marine Fisheries Service, 166 Water Street, Woods Hole, MA 02543, USA \\ Correspondence should be addressed to Michael D. Ford; michael.ford@noaa.gov
}

Received 19 July 2013; Revised 29 October 2013; Accepted 4 November 2013; Published 29 January 2014

Academic Editor: Heinrich Hühnerfuss

Copyright (C) 2014 M. D. Ford and J. S. Link. This is an open access article distributed under the Creative Commons Attribution License, which permits unrestricted use, distribution, and reproduction in any medium, provided the original work is properly cited.

\begin{abstract}
Previous descriptions have noted that the stomach samples of spiny dogfish, Squalus acanthias, showed a major increase in the overall occurrence and hence implied abundance of Ctenophora. This apparent and persistent gelatinous zooplankton outbreak is increasingly more common in the world's oceans. We briefly explore the energetic ramifications of ctenophores in the spiny dogfish diet, inferring that the presence of gelatinous zooplankton represents an ambient feeding strategy. Relative to other prey, ctenophores are not a high energy density prey item. However, given varying assumptions of the amount of ctenophores consumed, they may be an important staple in the diet of spiny dogfish. We also examine the utility of using spiny dogfish as a gelatinous zooplankton sampling device. Using five calculation methodologies, we provide bounds on potential abundance and biomass estimates of ctenophores in the Northeast U.S. shelf ecosystem. We then contextualize these findings relative to the implications for the Northeast U.S. and any large marine ecosystem.
\end{abstract}

\section{Introduction}

There have been several documented instances of gelatinous zooplankton blooms for a wide range of marine ecosystems. Both enclosed (e.g., Black Sea, Caspian Sea, Sea of Azov, and Sea of Marmara) and relatively enclosed/semiopen (e.g., Adriatic Sea, Baltic Sea, Gulf of Mexico, Bering Sea, and Mediterranean Sea) marine ecosystems have exhibited these blooms [1-5]. These increases in gelatinous zooplankton abundance have been variously attributed to eutrophication, water mass warming, and overfishing [1-4, 6-8]. These increases can also have significant, negative, ecosystem-wide impacts (e.g., [9-11]). Yet often the impact of these blooms on ecosystem trophodynamics and energy flow is poorly understood.

Additionally, sampling gelatinous zooplankton remains a major challenge for biological oceanography $[7,12]$. One way to overcome sampling difficulties for gelatinous organisms is to utilize fish as an in situ sampling device. Use of fish stomach contents has become increasingly widespread for obtaining basic, vital information on difficult-to-sample marine organisms [13-15].
In a prior study [16], we used fish stomachs (spiny dogfish, Squalus acanthias Linnaeus, 1758) to serve as a proxy estimate of relative abundance for Ctenophora in the Northeast U.S. (NEUS; Figure 1) continental shelf ecosystem. Our results from that work suggested that the relative occurrence of Ctenophora in spiny dogfish stomachs was increasing from 1981 to 2000, and after examining several assumptions, our results implied that ctenophore abundance was greatly increasing in the Northeast U.S. continental shelf ecosystem. Yet the scope (i.e., order of magnitude) of these and similar stomach-based estimates is rarely presented in terms of absolute abundance or biomass. There need to be some protocols to place bounds on estimates of abundance and biomass of these gelatinous zooplankton blooms in general but particularly as sampled by fish.

In our prior study [16], we did not attempt to scale our estimates to total abundance. We also did not evaluate how energetically important Ctenophora may be to their "sampler" fish, particularly with respect to other prey items. Thus, the objectives of this study were to evaluate the relative importance of ctenophores as prey for spiny dogfish in terms 


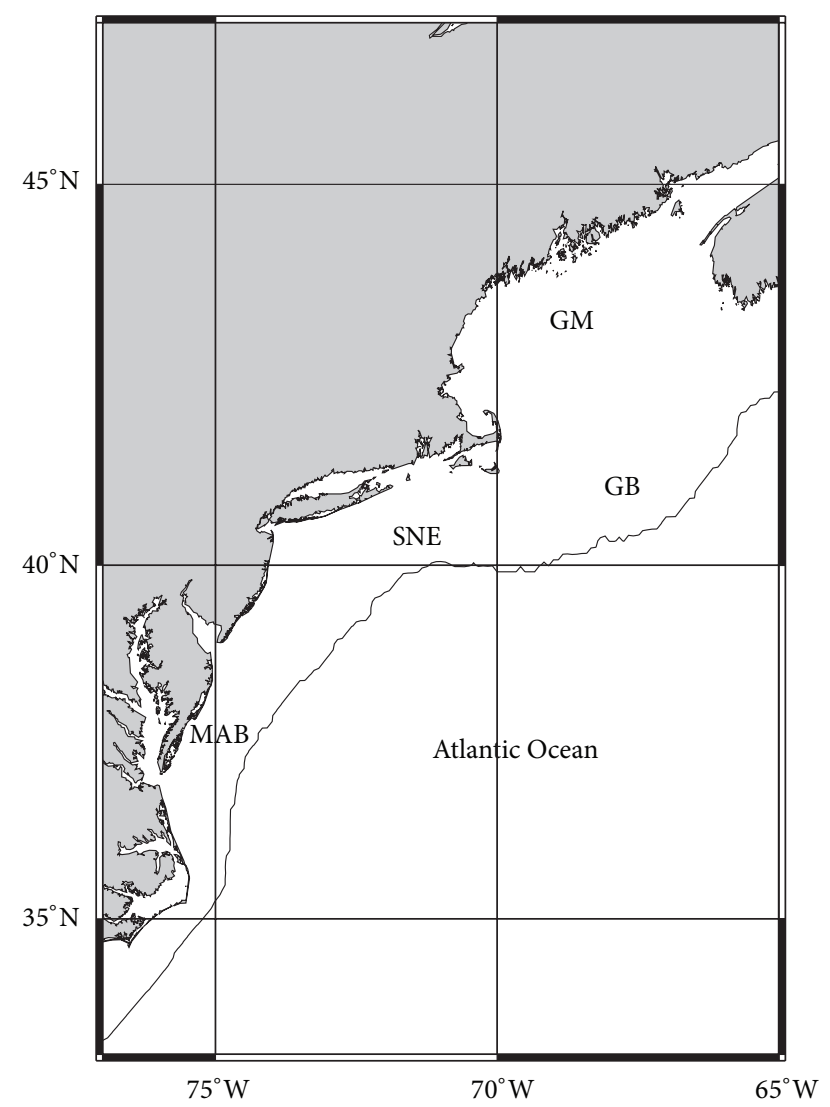

FIgURE 1: Map of the study area, the Northeast U.S. (NEUS) continental shelf. Common regions of Gulf of Maine (GM), Georges Bank (GB), Southern New England (SNE), and Middle Atlantic Bight (MAB) are highlighted.

of their energetic value and to provide bounds of probable magnitudes of abundance for these ctenophores in the NEUS. We do so by using several, simple feeding models with a range of assumptions. Although there are short-term or localized estimates of Ctenophora and other gelatinous zooplankton densities (e.g., $[10,17,18]$ ) for regions of the NEUS ecosystem, none are synoptic at broad spatial and temporal scales. Our work, although based upon field data, represents a modeling approach to provide some sensitivity to the estimates we were attempting to provide that are notably difficult using classical zooplankton approaches. Addressing the lack of good abundance estimates for gelatinous zooplankton in this way should provide a broader ecosystem context for the potential impact of these and similar gelatinous zooplankton blooms.

\section{Materials and Methods}

2.1. Background. The broad-scale, long-term sampling program of stomach contents of fishes from the Northeast U.S. continental shelf ecosystem (Figure 1) serves directly to identify changes in fish diets and indirectly to identify changes in the underlying ecosystem $[15,19,20]$. The standard National Marine Fisheries Service (NMFS) Northeast Fisheries Science Center (NEFSC) bottom trawl survey program has been conducted annually since 1963 [21, 22]. During these ongoing surveys, food habits data are collected from a variety of species. These multispecies surveys are designed to monitor trends in abundance and distribution and to provide samples to study the ecology of the large number of fish and invertebrate species inhabiting the region. Azarovitz [21] and NEFC [22] provide a more detailed description of the survey program.

Although the program started in 1963, we focused on our study on spiny dogfish stomachs $(n=43,489)$ collected from 1981 to 2000 throughout the entire range of the Northeast U.S. shelf surveys (i.e., from Cape Hatteras, NC, to Nova Scotia; Figure 1). Across the four regions depicted in the survey, the seasonally averaged abundance of spiny dogfish for the period of 1996-2000 ranged from 33 to 56 million dogfish per region. Full details of the food habits sampling and data are given in Link and Almeida [19] and are only summarized here with particular respect to spiny dogfish. During the period of the study (1981-2000), spiny dogfish stomachs were examined and prey-identified at sea immediately after the catch was sorted on deck. Thus, concerns over the degradation of any gelatinous zooplankton due to the effects of preservation in formalin or ethanol [9] or rapid digestion [23] are largely unmerited. Data on total stomach volume $\left(0.1 \mathrm{~cm}^{3}\right.$ minimum resolution), prey composition (\%), numbers, and lengths were collected shipboard. In addition, a conversion from volumetric measurement of prey $\left(\mathrm{cm}^{3}\right)$ to mass $(\mathrm{g})$ was executed to obtain biomass estimates of the food consumed. The range of annual average consumption of ctenophores in grams was 0.4 to $4.6 \mathrm{~g}$ with the time series average of $2.1 \mathrm{~g}$. The size of dogfish sampled ranged from juveniles $(\sim 35-40) \mathrm{cm}$ to large, mature females $(\sim 110 \mathrm{~cm})$ but were predominately the medium size classes $(50-80 \mathrm{~cm})$.

Ctenophora were readily identifiable in the stomachs of spiny dogfish, at sea upon macroscopic inspection, by their obvious firm-gelatin constitution, small and clear balllike shape, uniquely (relative to any other spiny dogfish prey) colored pinkish-gray masses, and particularly the ctene rows. Stomach contents identified as Ctenophora could have been Mnemiopsis leidyi, Pleurobrachia pileus, or Bolinopsis infundibulum, but it is beyond the scope of the present work to distinguish between them. Even after partial digestion, Ctenophora in spiny dogfish stomachs were identifiable, particularly the ctene. Spiny dogfish do not masticate Ctenophora; rather Ctenophora are ingested as whole prey items.

The traditional method for monitoring zooplankton levels in the Northeast U.S. shelf ecosystem has been plankton nets. However, plankton net surveys from 1977 to the present only record a very small number of observations of ctenophores (less than $2 \%$ of all tows taken). When compared with direct methods of sampling gelatinous zooplankton in the marine environment (e.g., nets), stomach sampling methods largely eliminated concerns of specimens breaking apart and becoming unidentifiable and/or indistinguishable $[7,12,24]$. Our modeling efforts used a range of digestion times from 0.25 hours to 24 hours since the digestion time of ctenophores in spiny dogfish has not been experimentally determined to our knowledge. 
TABLE 1: Energy density for common spiny dogfish (Squalus acanthias) prey items.

\begin{tabular}{|c|c|c|}
\hline Prey & $\mathrm{kJ} / \mathrm{g}$ & Reference \\
\hline Ctenophores-lower & 0.38 & {$[9,23]$} \\
\hline Ctenophores-upper & 0.84 & {$[9,23]$} \\
\hline \multicolumn{3}{|l|}{ Pandalus } \\
\hline shrimp-lower & 4.88 & {$[25]$} \\
\hline \multicolumn{3}{|l|}{ Pandalus } \\
\hline shrimp-upper & 9.52 & {$[25]$} \\
\hline Amphipods & 9.67 & {$[25]$} \\
\hline \multicolumn{3}{|l|}{ General } \\
\hline invertebrates-lower & 1.00 & {$[25]$} \\
\hline \multicolumn{3}{|l|}{ General } \\
\hline invertebrates-upper & 10.0 & {$[25]$} \\
\hline Medusae & 0.25 & {$[25]$} \\
\hline Ctenophores & 0.21 & {$[25]$} \\
\hline Cephalopods & 5.50 & {$[25]$} \\
\hline Bivalves & 1.54 & {$[25]$} \\
\hline Gastropods & 2.28 & {$[25]$} \\
\hline Zooplankton & 1.64 & [25] \\
\hline \multicolumn{3}{|l|}{ General } \\
\hline crustaceans-lower & 3.50 & {$[25]$} \\
\hline \multicolumn{3}{|l|}{ General } \\
\hline crustaceans-upper & 5.40 & {$[25]$} \\
\hline Tunicates & 0.40 & {$[25]$} \\
\hline Fish-lower & 4.00 & {$[26-28]$} \\
\hline Fish-upper & 7.00 & [26-28] \\
\hline Forage fish-lower & 10.0 & [26-28], Hartman pers. comm. \\
\hline Forage fish-upper & 20.0 & [26-28], Hartman pers. comm. \\
\hline
\end{tabular}

2.2. Energetic Contribution to Diet. The significance of ctenophores in the diet of spiny dogfish was explored in terms of consumption, energy density, and diet composition (percentage of weight) relative to other prey types. The caloric value of ctenophores is estimated to be between 90 and $200 \mathrm{cal} \mathrm{g}^{-1}$ wet weight $(1 \mathrm{cal}=4.1868 \mathrm{~J})$ [24]. Energy densities for other common spiny dogfish prey were taken from the literature (Table 1).

The energetic contribution of common prey items for spiny dogfish, including ctenophores, was estimated by using a simple product of percent diet composition, energy density, and mean amount of total food consumed. Additionally, we made calculations that also included the digestion rate of the prey item to estimate the energetic contribution of common prey items while accounting for the different digestion rates of prey body types.

2.3. Biomass Estimates. To place bounds on the estimates of potential abundance and biomass of ctenophores in the Northeast U.S. shelf ecosystem, we employed five calculation methodologies. The estimates here refer to biomass over the total area of the Northeast U.S. shelf ecosystem $\left(230,000 \mathrm{~km}^{2}\right)$. The five methodologies were a digestion time approach, a consumption model approach, simple frequency of occurrence, a swept volume model, and a plankton net method.

2.3.1. Digestion Time Method. Biomass of ctenophores within the whole of the NEUS was estimated using the mass of ctenophores in the stomachs of spiny dogfish and the estimated digestion time of ctenophores within spiny dogfish. The mass of ctenophores per year $\left(B_{\mathrm{ct}}\right)$ on the continental shelf was estimated as a function of the average mass of ctenophores found in dogfish stomachs in grams $(S)$, the estimated digestion time of a ctenophore in a dogfish stomach in hours ( $D$; scaled to 24 and multiplied by the number of days in a year), and the number of dogfish on the shelf $\left(N_{\operatorname{dog}}\right)$, where

$$
B_{\mathrm{ct}}=\left(\left(\frac{S}{D / 24}\right) \cdot 365\right) \cdot N_{\mathrm{dog}} .
$$

The amount of ctenophores found in dogfish $(S)$ came from stomach content sampling conducted on routine surveys described above. The number of dogfish present on the shelf ecosystem was taken from stock assessment estimates from the Northeast Fisheries Science Center [29, general survey techniques noted above]. We use the minimum, maximum, and average abundance of spiny dogfish from these estimates to bound the possible range $\left(N_{\mathrm{dog}}\right)$. To convert ctenophore biomass $\left(B_{\mathrm{ct}}\right)$ into ctenophore abundance $\left(N_{\mathrm{ct}}\right)$, we assumed an average individual mass of $0.36 \mathrm{~g}$ per ctenophore [23].

2.3.2. Consumption Model Method. The biomass of ctenophores on the shelf was also estimated using a consumption model method [30, 31]. In this case, the biomass of ctenophores per year was estimated as a function of the average mass of ctenophores found in dogfish stomachs in grams $(S)$ and the evacuation rate of ctenophores through dogfish $(E)$, where

$$
B_{\mathrm{ct}}^{\prime}=E \cdot 24 \cdot S \text {. }
$$

The 24 is the number of hours in a day, and the evacuation rate $(E)$ is defined as

$$
E=\alpha e^{\beta T_{p}},
$$

where $\alpha$ and $\beta$ are fitted coefficients [32]. This equation relates $E$ to temperature determined by laboratory studies and the literature [32], where $\beta$ is the slope found to be consistent between prey types and $\alpha$ is the intercept that is dependent on the prey type. For this study, $\alpha$ was set from 0.002 to 0.8 and $\beta$ was fixed to $0.115 . T_{p}$ is the mean temperature specified here as $14.5 \mathrm{C}$ (cf. [33]).

To scale to an annual, total estimate, $B_{\mathrm{ct}}^{\prime}$ was multiplied by the minimum swept area estimate of dogfish $\left(N_{\mathrm{dog}}\right)$ :

$$
B_{\mathrm{ct}}=N_{\mathrm{dog}} \cdot B_{\mathrm{ct}}^{\prime} \cdot 365 \text {, }
$$

where 365 is the number of days per year. To convert ctenophore biomass $\left(B_{\mathrm{ct}}\right)$ into ctenophore abundance $\left(N_{\mathrm{ct}}\right)$, we assumed an average individual mass of $0.36 \mathrm{~g}$ per ctenophore [23]. 
2.3.3. Simple Frequency of Occurrence in Dogfish Method. A simple method of estimating the biomass of ctenophores was used to estimate ctenophore biomass $\left(B_{\mathrm{ct}}\right)$ as a function of the percent frequency of occurrence of ctenophores in dogfish stomachs $(f)$, the number of dogfish on the continental shelf $\left(N_{\mathrm{dog}}\right)$, and the average mass of ctenophores found in the stomachs of dogfish $(S)$, where

$$
B_{\mathrm{ct}}=f \cdot N_{\mathrm{dog}} \cdot S .
$$

To convert ctenophore biomass $\left(B_{\mathrm{ct}}\right)$ into ctenophore abundance $\left(N_{c t}\right)$, we assumed an average individual mass of $0.36 \mathrm{~g}$ per ctenophore [23].

2.3.4. Swept Volume of Dogfish Method. The swept volume of a dogfish was defined as the product of the gape area and the time and distance a dogfish swims per day. We assumed agape width of $3 \mathrm{~cm}, 22$ hours of feeding in a day, and a swimming velocity of $1 \mathrm{~m} \mathrm{~s}^{-1}$. Observations of spiny dogfish morphology and swimming behavior were used to conservatively estimate gape width and swimming speed. The feeding time estimate was made to allow some time spent on nonfeeding activities (2 hours). Using the gape width as a diameter and scaled to the daily distance swum (product of speed and swimming time), the resulting swept volume $\left(V_{s}\right)$ for a dogfish was $40.72 \mathrm{~m}^{3}$. The mass of ctenophores per dogfish per day $\left(B_{\mathrm{ct}-}^{\prime}\right.$; scaled by 24 for a daily estimate) could be estimated by using this swept volume $\left(V_{s}\right)$, the average mass of ctenophores found in the stomachs of dogfish $(S)$, and the percent frequency of occurrence of ctenophores in dogfish stomachs $(f)$, where

$$
B_{\mathrm{ct}}^{\prime}=V_{s} \cdot S \cdot f \cdot 24
$$

Using the volume of water $\left(V_{\text {shelf }}\right)$ in each of the four regions (the Gulf of Maine (GoM), Georges Bank (GB), Southern New England (SNE), and the Middle Atlantic Bight (MAB)) on the continental shelf, the number of days per year, and the number of dogfish present in each region $\left(N_{\text {dog-reg }}\right)$, the biomass of ctenophores, $B_{\mathrm{ct}}$, could be calculated, where

$$
B_{\mathrm{ct}}=B_{\mathrm{ct}}^{\prime} \cdot 365 \cdot V_{\text {shelf }} \cdot N_{\text {dog-reg }} .
$$

Estimates of water volume $\left(\mathrm{m}^{3}\right)$ were calculated from NEFSC estimates of area and average depth for each region. The numbers of dogfish found in each region were also from NEFSC survey estimates. These were then integrated into a total for the entire shelf. To convert ctenophore biomass $\left(B_{\mathrm{ct}}\right)$ into ctenophore abundance $\left(N_{\mathrm{ct}}\right)$, we assumed an average individual mass of $0.36 \mathrm{~g}$ per ctenophore [23].

2.3.5. Plankton Net Method. Prior ctenophore abundance estimates for the NEUS shelf were estimated directly, systemwide, as part of the Energy Modeling and Analysis Exercise (EMAX) [34]. Using data from plankton tows, estimates of average abundance and biomass of ctenophores for the entire time period were calculated in each of the four regions of the continental shelf previously described [35]. These tows were routine $60 \mathrm{~cm}, .333 \mathrm{~mm}$ mesh bongo tows from the NMFS EcoMon sampling program. Seasonal variation was

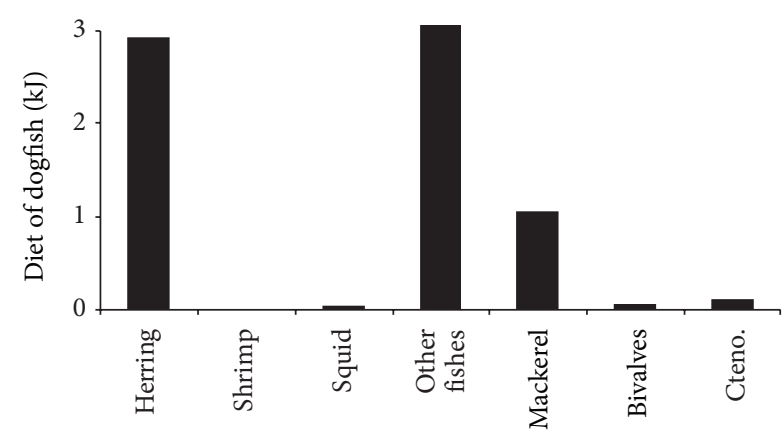

FIGURE 2: Energy density of selected common prey types scaled by diet composition.

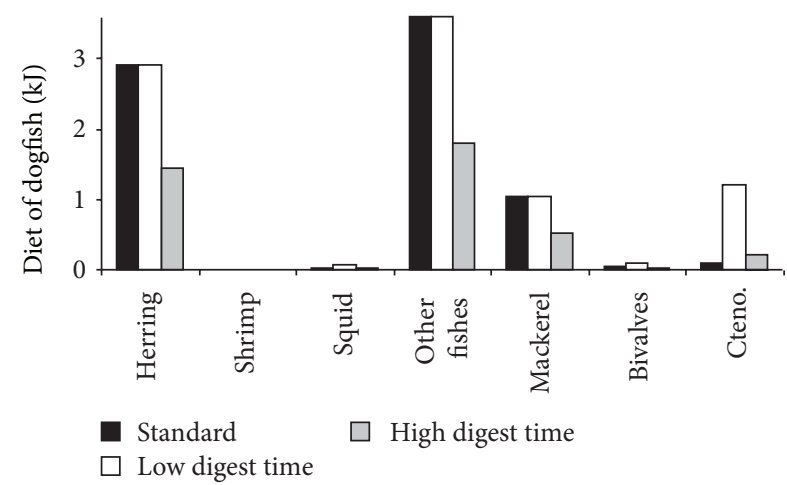

FIGURE 3: Energy density of common prey items scaled for diet composition and digestion time.

not accounted for in the model, but EMAX [34] indicates higher concentrations during the periods of May-June and September-October. Regionally, in this data set, the Middle Atlantic Bight and Southern New England had higher concentrations than Georges Bank and the Gulf of Maine. The area of each region was used to determine a weighted abundance of ctenophores, which were then integrated for the entire shelf.

\section{Results}

3.1. Energetics. The energy density $\left(\mathrm{KJg}^{-1}\right)$ of common spiny dogfish prey, including ctenophores, indicated that herring and mackerel had the highest energy density, whereas ctenophores had the lowest energy density (Table 1). When energy density was scaled by diet composition, small pelagic fishes such as herring, mackerel and other fishes were the largest energy contributors to spiny dogfish diet (Figure 2).

When digestion time was factored into the scaled energy density calculations, the relative significance of ctenophores increased. Under the lowest digestion time, ctenophores contributed as much energy to the diet of spiny dogfish as mackerel but were still much lower than other fishes (Figure 3).

\subsection{Biomass Estimates}

3.2.1. Digestion Time Method. Considering a range of possible digestion times for ctenophores in dogfish, the mean 


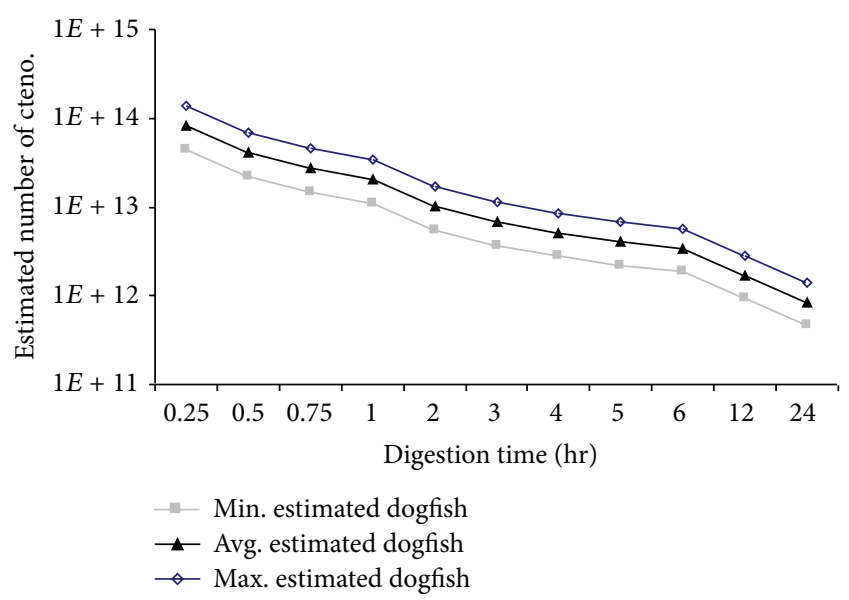

FIgURE 4: Estimated number of ctenophores as a function of ctenophore digestion time $(\mathrm{h})$ for minimum, maximum, and average dogfish abundance estimates.

estimated number of ctenophores in this continental shelf ecosystem ranged from $8.1 \times 10^{13}$ at the fastest digestion time of $0.25 \mathrm{~h}$ to $8.5 \times 10^{11}$ at the slowest digestion time of $24 \mathrm{~h}$ (Figure 4). The different estimates for the number of dogfish (minimum, average, or maximum) did not notably impact the total abundance estimates of ctenophores for any given digestion time; results varied less than one half of an order of magnitude. Most estimates were similar across the abundance of spiny dogfish and given range of digestion times, typically on the order of $10^{12}$ to $10^{13}$. The mean estimates of biomass ranged from 306 to approximately 30,000 thousand metric tons, again depending upon the time of digestion and estimate of dogfish abundance. The majority of the biomass estimates ranged between 5,000 and 15,000 thousand metric tons.

3.2.2. Consumption Model Method. Considering a range of digestibility coefficients $(\alpha)$ for ctenophores, the mean estimated number of ctenophores in this continental shelf ecosystem ranged from $2.2 \times 10^{10}$ given the lowest $\alpha$ to $8.7 \times$ $10^{13}$ for the highest $\alpha$ (Figure 5). Differences in the range of dogfish abundance estimates similarly resulted in a difference in the ctenophore estimate of less than half an order of magnitude. Most abundance estimates were on the order of $10^{11}$ to $10^{12}$ ctenophores in the ecosystem. The mean biomass estimates ranged from 7.8 to approximately 31,000 thousand metric tons. Again, the minimum or maximum abundance estimate of spiny dogfish used only changed the results by less than one half of an order of magnitude.

3.2.3. Simple Frequency of Occurrence in Dogfish Method. When using the simple frequency of occurrence method, the mean number of ctenophores was $1.6 \times 10^{8}$, ranging from $3.7 \times 10^{7}$ to $1.3 \times 10^{9}$, using the minimum and maximum estimates of dogfish abundance (Figure 6). The biomass estimates of ctenophores using this method were all notably less than 0.1 thousand metric tons.

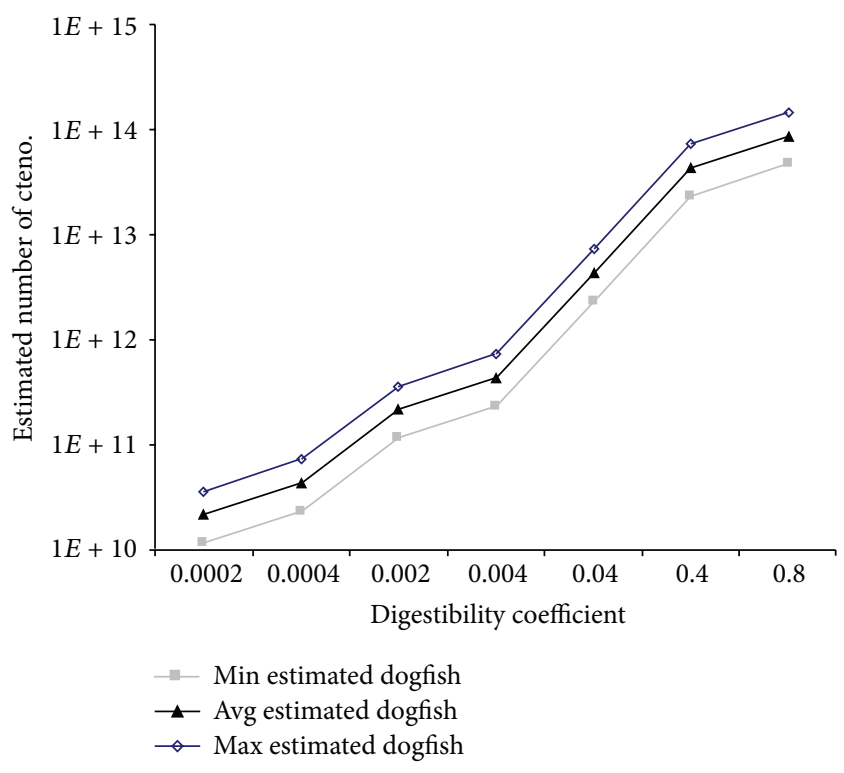

FIGURE 5: Estimated number of ctenophores as a function of digestibility coefficient $(\alpha)$ for minimum, maximum, and average dogfish abundance estimates.

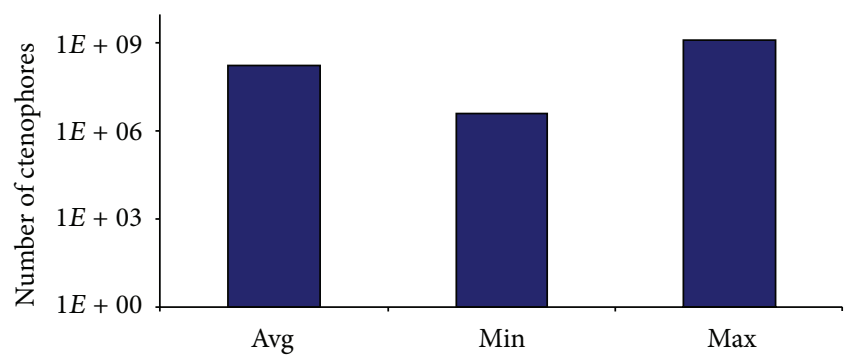

FIGURE 6: Estimates of ctenophore abundance using the simple frequency of occurrence in dogfish method. Results presented for minimum, maximum, and average dogfish abundance estimates.

3.2.4. Swept Volume of Dogfish Method. There were an estimated $1.2 \times 10^{10}$ ctenophores per year in the entire continental shelf ecosystem using the swept volume method. The estimate of ctenophore biomass was 4.2 thousand MT from this method.

3.2.5. Plankton Net Method. Using the plankton net and associated methodology described in EMAX, there were approximately $8.3 \times 10^{13}$ ctenophores in the entire continental shelf ecosystem. This estimate was derived from the average ctenophore concentration $\left(10 \mathrm{~m}^{-2}\right)$ of $22,88,20$, and 6 for the Middle Atlantic Bight, Southern New England, Georges Bank, and Gulf of Maine regions, respectively. The estimate of total ctenophore biomass was approximately 30,000 thousand MT.

3.2.6. Comparison and Context. Overall, the five methods for determining the abundance of ctenophores spanned six orders of magnitude, with mean values ranging between 


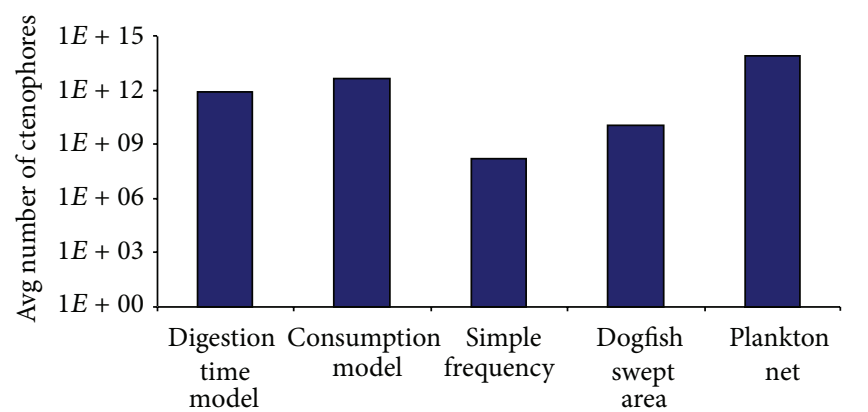

(a)

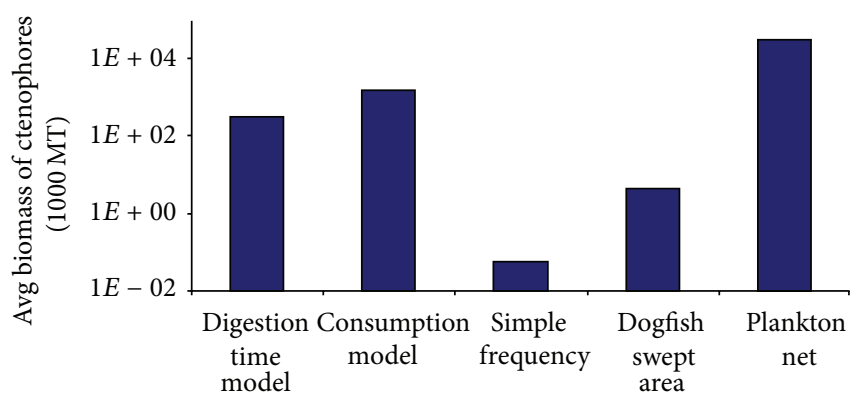

(b)

FIGURE 7: Average number (a) and average biomass (b) of ctenophores (1000 MT) as estimated from the different methods.

$10^{8}$ and $10^{13}$ (Figure 7). Total mean biomass estimates were between $0.5 \mathrm{MT}$ and 30,000 thousand MT.

\section{Discussion}

4.1. Energetic Contribution to Diet. Ctenophores have a low energy density relative to other spiny dogfish prey such as mackerel, herring, shrimp, and squid. When the energy densities of individual prey items are scaled by diet composition, small pelagic fishes become the most energetically dominant component of the spiny dogfish diet.

Our results do indicate that faster digestion times for gelatinous zooplankton can increase the energetic importance of ctenophores in dogfish. We calculated the diet-scaled energetic importance (energy density) of ctenophores for a range of digestion rates from $0.25 \mathrm{~h}$ to $24 \mathrm{~h}$. Our estimates indicate more than a fivefold difference in energy contributed by ctenophores when digestion times range from even just 0.75 to $4 \mathrm{~h}$. This range of digestion times is shorter than other common prey items like mackerel. While we do not have empirical data for the digestion time of ctenophores in spiny dogfish, we do have empirically derived digestion rates of a tentaculate ctenophore Pleurobrachia bachei in chum salmon, Oncorhynchus keta of $1 \mathrm{~h}$ [23]. While we recognize differences in relative stomach size and intestine length and expect differences in gut passage times between spiny dogfish and chum salmon, to our knowledge, experimentally determined digestion rates for ctenophores in dogfish do not exist. Using the empirical salmon data as a rough estimate for the digestion time in spiny dogfish, ctenophores might contribute as much energy as mackerel to the spiny dogfish diet. However, the final conclusion is that even if we assume a $1 \mathrm{~h}$ digestion time, ctenophores are still a very low energy prey item for spiny dogfish and other fishes that eat them relative to most other prey items. As stated in previous reviews, future experiments to determine digestion rates would allow for more accurate determination of the energetic contribution of ctenophores in the diet of fishes $[9,11]$.

We infer from these results that spiny dogfish feed on ctenophores in an opportunistic feeding mode, eating them as encountered while swimming in the water column. This implies that spiny dogfish neither select for nor avoid ctenophores. It may be that ctenophores serve as a supplementary food source allowing spiny dogfish to maintain some basic energy demands, but it is unlikely that spiny dogfish glean a large portion of their bioenergetic demands solely from ctenophores. We suspect that this is generally true for other fishes that prey upon gelatinous zooplankton, with a few exceptions (e.g., Stromateid fishes such as Stromateus brasiliensis Fowler 1906 or Seriolella porosa Guichenot, 1848 that feed almost exclusively on ctenophores) [35]. Yet thus far there are no fishes known to consume solely pelagic coelenterates as their only prey [11].

4.2. Biomass Estimates. Our model analyses and assumptions imply a level of uncertainty in amount of ctenophores consumed by spiny dogfish in the NEUS on the range of six orders of magnitude. Abundance estimates were on the order of $10^{8}$ to $10^{13}$ individuals in the NEUS. Estimates for biomass were similarly quite widespread, roughly ranging between $10^{1}$ and $10^{5}$ thousand MT. These estimates are quite variable and encompass quite a large range but do provide a reasonable bound of possible estimates of ctenophore abundance. This work in many ways represents a rudimentary sensitivity analysis among different methods and serves to provide a bound about the true ctenophore abundance, outside of which most estimates are likely to be ecologically unfeasible.

Some key assumptions in the different methods we used all merit further investigation. Chief among them is the identification of major unknowns: digestion time, ctenophore weight, and true abundance of "sampler" fish. Obviously, there is a tradeoff among the methods used in terms of data or parameter requirements and simplicity. That most of our estimates provided values of similar orders of magnitude adds confidence to the range of estimates presented.

Furthermore, a recent study from Narragansett Bay, Rhode Island, USA, reported concentrations of ctenophores between $0.1 \mathrm{~m}^{-3}$ and $1000 \mathrm{~m}^{-3}$ [36]. Using the rough volume of Narragansett Bay, this would be a total abundance from approximately $2.97 \times 10^{8}$ to approximately $2.97 \times 10^{12}$ and a biomass between 0.386 and 3859 thousand MT. Similarly, the Sea of Azov experienced an explosion of Mnemiopsis leidyi ranging from 32 to $106 \mathrm{~g} \mathrm{~m}^{3}$ [37]. Using a rough estimate for the volume of the Sea of Azov, this density suggests an approximate biomass between $1.56 \times 10^{4}$ and $5.18 \times$ $10^{4}$ thousand MT. Conversely, estimates of Ctenophora and other gelatinous zooplankton densities (e.g., $[10,17,18])$ for regions of the NEUS ecosystem (e.g., Gulf of Maine, Georges 
Bank) can be higher than those presented here, but none of those are synoptic at broad spatial and temporal scales needed to appropriately estimate Ctenophora abundance for the entire NEUS ecosystem. But again, calculated estimates from these other studies and the other ecosystems noted above are of the same magnitude as ours and confirm that when ctenophore blooms occur, they are roughly at this level of density. In short, because the many different approaches we used provide estimates on the same magnitude as other studies, we have higher confidence that our more simplistic modeling approaches have reasonably bounded this estimation problem.

Ctenophora and other gelatinous zooplankton are inherently difficult to sample and survey, particularly at synoptic temporal and spatial scales $[7,12]$. The merits of using a novel sampling device fish stomachs have been discussed elsewhere [13-15], particularly for ctenophores [16]. Providing some sense of scaling to a system-wide estimate and some sense of bounding to those estimates is a useful outcome of this work. That we have been able to provide a set of reasonable bounds of abundance estimates is not trivial.

The spiny dogfish appears to be a good sampler for ctenophores that can support studies like this one. Previous studies $[16,20]$ have shown that the diet composition of Ctenophora in the spiny dogfish has remained consistent and without a clear trend in the amount eaten, suggesting a relative constancy in the factors that determine the amount of ctenophora they consume. Further confidence is gained in the stability within the diet of the spiny dogfish during this study period. Levels of consumption of major functional groups of prey (e.g., small forage fishes) have remained constant, even when certain species might fluctuate. When all other factors about the changes in ctenophore occurrence in the spiny dogfish are considered, we are left with accepting that these data represent a good proxy for the change in ctenophore abundance [16].

The amount of gelatinous zooplankton in the world's oceans remains a major question. The examples from other ecosystems (e.g., [1-5]) suggest that there may be many more gelatinous zooplankton than we suspect. The implications of having high gelatinous zooplankton biomass in an ecosystem have been well chronicled (e.g., [9-11]) and are mostly negative. While ctenophores were the focus of this study, it should be pointed out that according to NEFSC plankton survey data, Northeast U.S. shelf ecosystem gelatinous zooplankton includes ctenophores, siphonophores, salps, hydromedusae, and scyphomedusae. Potential impacts vary by ecosystem but can include significant predation on fish eggs, fish larvae, and heightened competition for zooplankton prey [11]. Ctenophores, depending on species, might affect fish egg concentrations ( $M$. leidyi) or, inter alia, compete for zooplankton prey in the case of $P$. pileus [11]. Thus, it has become increasingly imperative that we develop methods to estimate and measure gelatinous zooplankton in situ on a synoptic scale. The approaches we present here highlight a few possible ways to estimate the abundance and biomass and reasonably place bounds on those estimates, for hard to sample gelatinous zooplankton.

\section{Conflict of Interests}

The authors declare that there is no conflict of interests regarding the publication of this paper.

\section{Acknowledgments}

The authors thank the numerous staff at the NEFSC, past and present, who have collected fish stomachs on the routine surveys. They also thank two anonymous reviewers for their constructive comments on earlier drafts of this paper.

\section{References}

[1] J. E. Purcell, W. M. Graham, and H. J. C. Dumont, Jellyfish Blooms: Ecological and Societal Importance: Proceedings of the International Conference on Jellyfish Blooms, vol. 451, Hydrobiologia, 2001.

[2] T. A. Shiganova, Z. A. Mirzoyan, E. A. Studenikina et al., "Population development of the invader ctenophore Mnemiopsis leidyi, in the Black Sea and in other seas of the Mediterranean basin," Marine Biology, vol. 139, no. 3, pp. 431-445, 2001.

[3] R. D. Brodeur, H. Sugisaki, and G. L. Hunt Jr., "Increases in jellyfish biomass in the Bering Sea: implications for the ecosystem," Marine Ecology Progress Series, vol. 233, pp. 89-103, 2002.

[4] A. C. Gucu, "Can overfishing be responsible for the successful establishment of Mnemiopsis leidyi in the Black Sea?" Estuarine, Coastal and Shelf Science, vol. 54, no. 3, pp. 439-451, 2002.

[5] M. Bilio and U. Niermann, "Is the comb jelly really to blame for it all? Mnemiopsis leidyi and the ecological concerns about the Caspian Sea," Marine Ecology Progress Series, vol. 269, pp. 173183, 2004.

[6] B. K. Sullivan, D. Van Keuren, and M. Clancy, "Timing and size of blooms of the ctenophore Mnemiopsis leidyi in relation to temperature in Narragansett Bay, RI," Hydrobiologia, vol. 451, pp. 113-120, 2001.

[7] T. Weisse, M.-T. Gomoiu, U. Scheffel, and F. Brodrecht, "Biomass and size composition of the Comb Jelly Mnemiopsis sp. in the north-western Black Sea during spring 1997 and summer 1995," Estuarine, Coastal and Shelf Science, vol. 54, no. 3, pp. 423-437, 2002.

[8] J. E. Purcell, "Climate effects on formation of jellyfish and ctenophore blooms: a review," Journal of the Marine Biological Association of the United Kingdom, vol. 85, no. 3, pp. 461-476, 2005.

[9] M. N. Arai, "Interactions of fish and pelagic coelenterates," Canadian Journal of Zoology, vol. 66, no. 9, pp. 1913-1927, 1988.

[10] C. E. Mills, "Medusae, siphonophores, and ctenophores as planktivorous predators in changing global ecosystems," ICES Journal of Marine Science, vol. 52, no. 3-4, pp. 575-581, 1995.

[11] J. E. Purcell and M. N. Arai, "Interactions of pelagic cnidarians and ctenophores with fish: a review," Hydrobiologia, vol. 451, pp. 27-44, 2001.

[12] W. M. Hamner, L. P. Madin, A. L. Alldredge, R. W. Gilmer, and P. P. Hamner, "Underwater observations of gelatinous zooplankton: sampling problems, feeding biology, and behavior," Limnology and Oceanography, vol. 20, pp. 907-917, 1975.

[13] L. Fahrig, G. R. Lilly, and D. S. Miller, "Predator stomachs as sampling tools for prey distribution: atlantic cod (Gadus 
morhua) and capelin (Mallotus villosus)," Canadian Journal of Fisheries and Aquatic Sciences, vol. 50, no. 7, pp. 1541-1547, 1993.

[14] C. L. J. Frid and S. J. Hall, "Inferring changes in North Sea benthos from fish stomach analysis," Marine Ecology Progress Series, vol. 184, pp. 183-188, 1999.

[15] J. S. Link, "Using fish stomachs as samplers of the benthos: integrating long-term and broad scales," Marine Ecology Progress Series, vol. 269, pp. 265-275, 2004.

[16] J. S. Link and M. D. Ford, "Widespread and persistent increase of Ctenophora in the continental shelf ecosystem off NE USA," Marine Ecology Progress Series, vol. 320, pp. 153-159, 2006.

[17] L. P. Madin, S. M. Bollens, E. Horgan et al., "Voracious planktonic hydroids: unexpected predatory impact on a coastal marine ecosystem," Deep-Sea Research Part II: Topical Studies in Oceanography, vol. 43, no. 7-8, pp. 1823-1829, 1996.

[18] S. R. Avent, S. M. Bollens, M. Butler, E. Horgan, and R. Rountree, "Planktonic hydroids on Georges Bank: ingestion and selection by predatory fishes," Deep-Sea Research Part II: Topical Studies in Oceanography, vol. 48, no. 1-3, pp. 673-684, 2001.

[19] J. S. Link and F. P. Almeida, An Overview and History of the Food Web Dynamics Program of the Northeast Fisheries Science Center, NOAA Technical Memorandum NMFS-NE159, Woods Hole, Mass, USA, 2000.

[20] J. S. Link, J. K. T. Brodziak, S. F. Edwards et al., "Marine ecosystem assessment in a fisheries management context," Canadian Journal of Fisheries and Aquatic Sciences, vol. 59, no. 9, pp. 1429-1440, 2002.

[21] T. R. Azarovitz, "A brief historical review of the Woods Hole Laboratory trawl survey time series Bottom trawl surveys," Canadian Special Publication of Fisheries and Aquatic Sciences, vol. 58, pp. 62-67, 1981.

[22] Northeast Fisheries Center, An Evaluation of the Bottom Trawl Survey Program of the Northeast Fisheries Center, NOAA Technical Memorandum NMFS-F/NEC-52, National Marine Fisheries Service, Woods Hole, Mass, USA, 1988.

[23] M. N. Arai, D. W. Welch, A. L. Dunsmuir, M. C. Jacobs, and A. R. Ladouceur, "Digestion of pelagic Ctenophora and Cnidaria by fish," Canadian Journal of Fisheries and Aquatic Sciences, vol. 60, no. 7, pp. 825-829, 2003.

[24] T. G. Bailey, J. J. Torres, M. J. Youngbluth, and G. P. Owen, "Effect of decompression on mesopelagic gelatinous zooplankton: a comparison of in situ and shipboard measurements of metabolism," Marine Ecology Progress Series, vol. 113, no. 1-2, pp. 13-28, 1994.

[25] F. W. Steimle and R. J. Terranova, "Energy equivalents of marine organisms from the continental shelf of the temperate Northwest Atlantic," Journal of Northwest Atlantic Fishery Science, vol. 6, pp. 117-124, 1985.

[26] K. J. Hartman and S. B. Brandt, "Estimating energy density of fish," Transactions of the American Fisheries Society, vol. 124, no. 3, pp. 347-355, 1995.

[27] J. W. Lawson, A. M. Magalhães, and E. H. Miller, "Important prey species of marine vertebrate predators in the northwest Atlantic: proximate composition and energy density," Marine Ecology Progress Series, vol. 164, pp. 13-20, 1998.

[28] J. Pedersen and J. R. G. Hislop, "Seasonal variations in the energy density of fishes in the North Sea," Journal of Fish Biology, vol. 59, no. 2, pp. 380-389, 2001.

[29] Northeast Fisheries Science Center, 37th Northeast Regional Stock Assessment Workshop (37th SAW) Advisory Report, Northeast Fishery Science Center Reference Document 03-17,
National Marine Fisheries Service, Northeast Fisheries Science Center, Woods Hole, Mass, USA, 2003.

[30] D. M. Eggers, "Factors in interpreting data obtained by diel sampling of fish stomachs," Journal of the Fisheries Research Board of Canada, vol. 34, pp. 290-294, 1977.

[31] J. M. Elliot and L. Persson, "The estimation of daily rates of food consumption for fish," Journal of Animal Ecology, vol. 47, pp. 977-991, 1978.

[32] J. S. Link, L. P. Garrison, and F. P. Almeida, "Ecological interactions between Elasmobranchs and groundfish species on the Northeastern U.S. Continental Shelf. I. Evaluating Predation," North American Journal of Fisheries Management, vol. 22, pp. 550-562, 2002.

[33] M. H. Taylor, C. Bascuñán, and J. P. Manning, Description of the 2004 Oceanographic Conditions on the Northeast Continental Shelf, Northeast Fishery Science Center Reference Document 05-03, National Marine Fisheries Service, Northeast Fisheries Science Center, Woods Hole, Mass, USA, 2005.

[34] J. S. Link, C. A. Griswold, E. T. Methratta, and J. Gunnard, Eds., Documentation for the Energy Modeling and Analysis EXercise (EMAX), Northeast Fisheries Science Center Reference Document 06-15, US Department of Commerce, National Marine Fisheries Service, Woods Hole, Mass, USA, 2006.

[35] H. W. Mianzan, N. Mari, B. Prenski, and F. Sanchez, "Fish predation on neritic ctenophores from the Argentine continental shelf: a neglected food resource?" Fisheries Research, vol. 27, no. 1-3, pp. 69-79, 1996.

[36] J. H. Costello, B. K. Sullivan, D. J. Gifford, D. Van Keuren, and L. J. Sullivan, "Seasonal refugia, shoreward thermal amplification, and metapopulation dynamics of the ctenophore Mnemiopsis leidyi in Narragansett Bay, Rhode Island," Limnology and Oceanography, vol. 51, no. 4, pp. 1819-1831, 2006.

[37] S. P. Volovik, Z. A. Myrzoyan, and G. S. Volovik, "Mnemiopsis leidyi in the Azov Sea: biology, population dynamics, impact to the ecosystem and fisheries," in Proceedings of the ICES Statutory Meeting, pp. 1-69, CM Documents, 1993. 

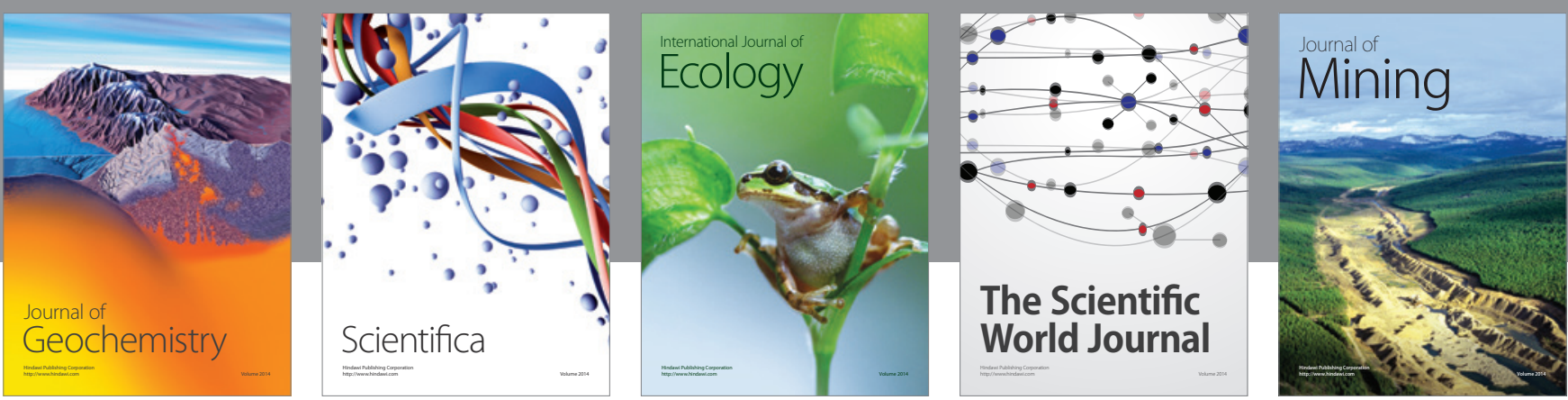

The Scientific World Journal
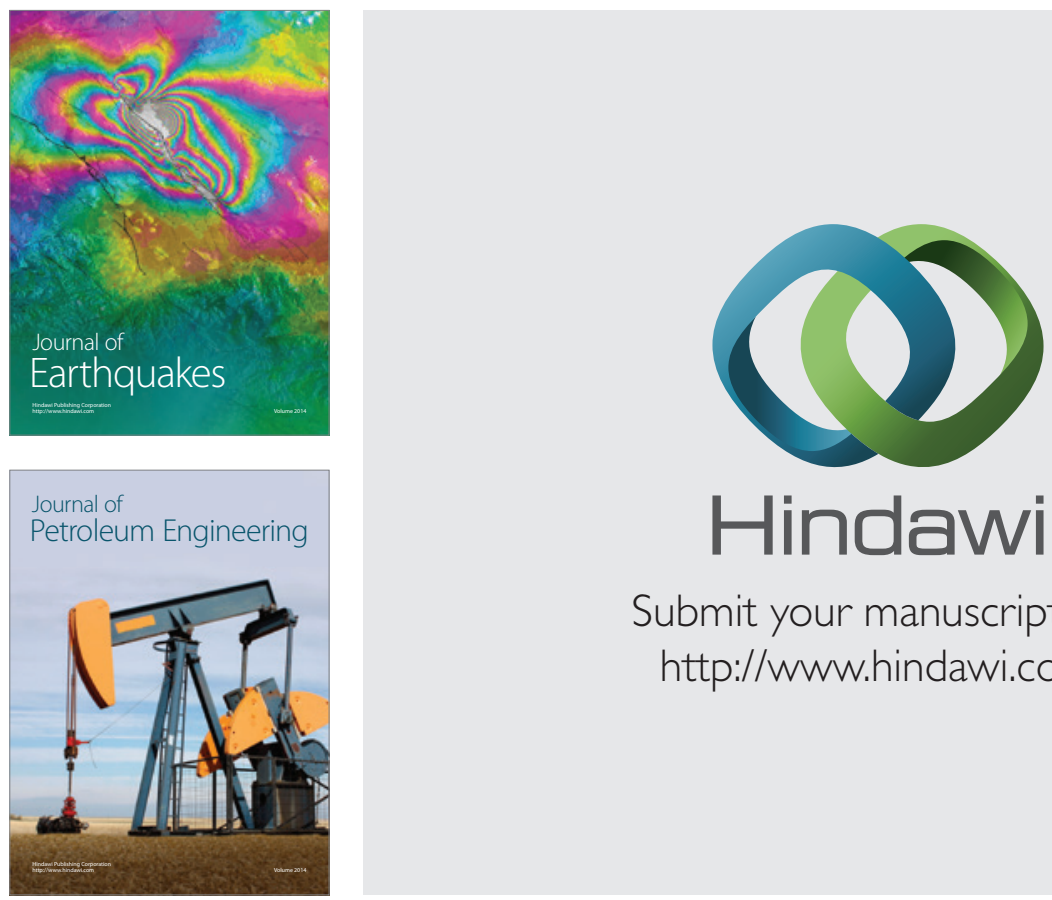

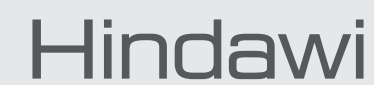

Submit your manuscripts at

http://www.hindawi.com
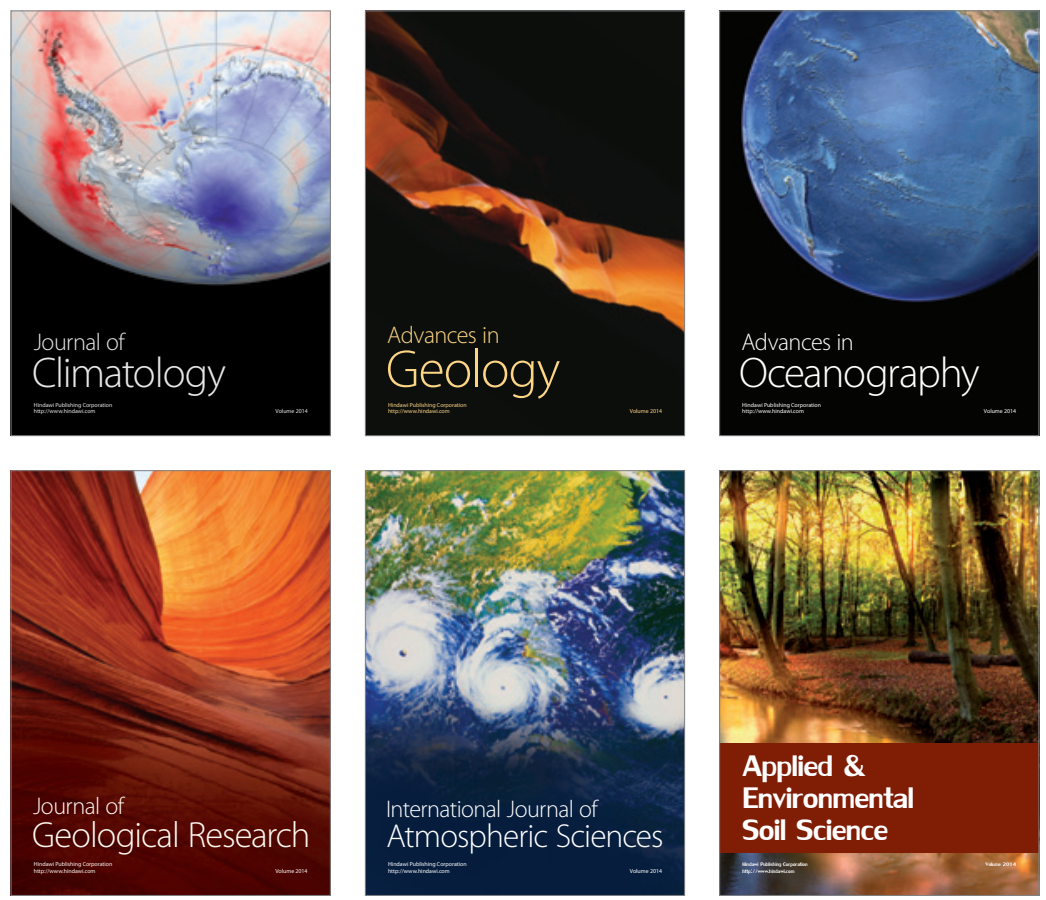
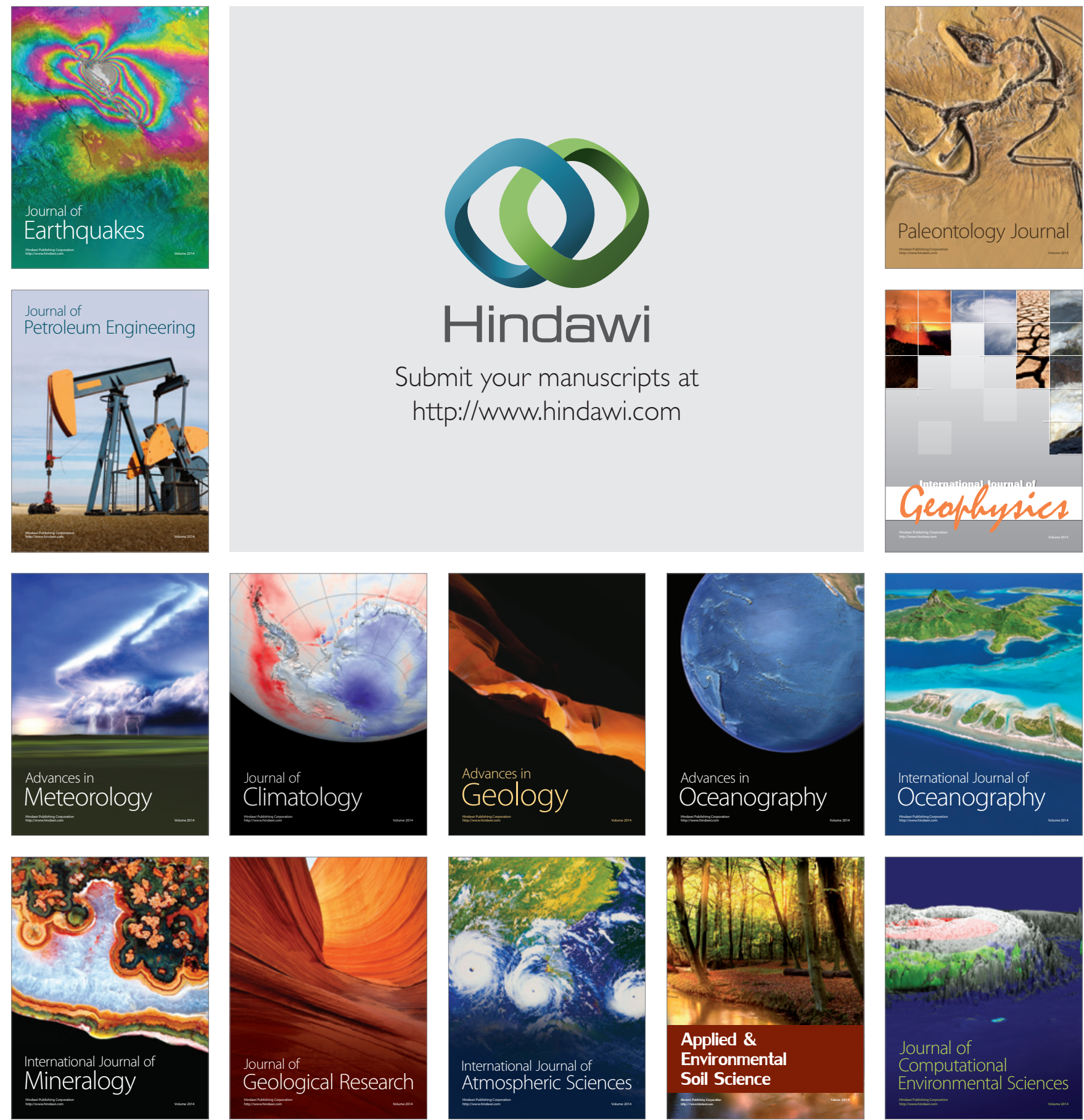